\title{
MORPHOLOGY AND MECHANICAL PROPERTIES OF NANOSTRUCTURED THERMOSET/BLOCK COPOLYMER BLENDS WITH CARBON NANOPARTICLES
}

\author{
Mario Martin-Gallego ${ }^{1 *}$, Raquel Verdejo ${ }^{1}$, Adrian Gestos ${ }^{2}$, Miguel A. Lopez- \\ Manchado $^{1}$, Qipeng Guo ${ }^{2 *}$ \\ ${ }^{1}$ Instituto de Ciencia y Tecnologia de Polimeros, ICTP-CSIC, Juan de la Cierva, 3 \\ 28006-Madrid, Spain. \\ ${ }^{2}$ Institute for Frontier Materials, Deakin University, Locked Bag 2000, Geelong, \\ Victoria 3220, Australia.
}

\begin{abstract}
:
Here we report the effect of multi-walled carbon nanotubes (MWCNTs) and thermally reduced graphene (TRG) on the miscibility, morphology and final properties of nanostructured epoxy resin with an amphiphilic poly(ethylene oxide)-poly(propylene oxide)-poly(ethylene oxide) (PEO-PPO-PEO) triblock copolymer. The addition of nanoparticles did not have any influence on the miscibility of PEO-PPO-PEO copolymer in the resin. However, MWCNTs and TRG reduced the degree of crystallinity of the PEO-rich microphases in the blends above $10 \mathrm{wt}$ \% of copolymer while they did not change the phase morphology at the nanoscale, where PPO spherical domains of 20-30 nm were found in all the samples studied. A synergic effect between the self-assembled nanostructure and the nanoparticles on the toughness of the cured resin was observed. In addition, the nanoparticles minimized the negative effect of the copolymer on the elastic modulus and glass transition temperature in the resin.
\end{abstract}

Keywords: A. Polymer-matrix composites (PMCs); A. Nano-structures; B. Fracture toughness.

*Corresponding author: m.martingallego@ictp.csic.es Tel: +34 91258742 


\section{INTRODUCTION:}

Epoxies are found in a wide range of applications in different sectors including building, electronics, aircrafts, automobile and so on[1-4]. Cured epoxy resins often possess high performance properties, however due to their highly crosslinked structure they present high brittleness limiting their final application in many cases. Hence, enormous research efforts have been taken in an attempt to improve the toughness of thermosetting polymers. One of the most successful routes is to incorporate soft polymer modifiers like elastomers[5], thermoplastics[6], hyperbranched polymers[7] or rigid fillers[8]. In all cases, the finer and smaller the morphology of the second phase, the greater the enhancement in the toughness of brittle polymers is[9].

In this context, the use of nanostructured systems seems to be one of the most appropriate strategies to modify the final properties of polymers. For this reason, nanostructures generated by the addition of amphiphilic block copolymers to the epoxy formulation have attracted great attention in recent years. Since the first work reported by Hilmyer et al.[10] describing self-assembled structures in thermosetting polymers, two key types of block copolymers (BC) have been used as toughening agents. The first type are reactive BCs whose epoxy miscible group is reactive towards the epoxy monomer or hardener and the developed nanostructure can be fixed before macrophase separation occurs. A reactive $\mathrm{BC}$ can be produced by the epoxidation of one of its groups[11] or by synthesizing the full BC through complex reactions[12]. The second type are non-reactive $\mathrm{BCs}$ which are the most widely studied, and includes a range a variants such as, poly(styrene)-poly(2-vinylpyridine), polystyrene-block-poly(ethylene oxide) or poly(epsilon-caprolactone)-block-polybutadiene-block-poly(epsiloncaprolactone), among others. A detailed review of BCs used in epoxy toughening can be found elsewhere[13]. Poly(ethylene glycol)-poly(propylene glycol)-poly(ethylene 
glycol), (PEO-PPO-PEO), represents one of the most important BCs employed to nanostructure epoxy resins. The popularity of PEO-PPO-PEO is due to its commercial availability, including different ratios of each block as well as the simplicity of the experimental procedure and the absence of any chemical synthesis or reaction with the epoxy system. For PEO-PPO-PEO epoxy blends, the formation of the self-assembled nanostructure depends on the curing conditions and the inner characteristics of the $\mathrm{BC}[14-16]$. A common problem with adding BCs to epoxy resins is that poor miscibility between the two materials can result in a microphase separation of one block of the $\mathrm{BC}$, which minimizes the toughening effect of the $\mathrm{BC}$. In addition, the $\mathrm{BCs}$ can have a negative effect on the Young's modulus and glass transition of the cured resin.

In addition to $\mathrm{BCs}$, nanoparticles like carbon nanotubes and graphene have also been used to enhance the mechanical properties of epoxy resins and in particular the toughness $[8,17,18]$.

In the present work, we have analyzed the possible synergic effect between the self-assembled nanostructure of the $\mathrm{BC}$ and the nanoparticles on the toughness of the cured resin. The idea is that the addition of PEO-PPO-PEO should induce a nanostructure within the epoxy matrix that would enable a better dispersion of the nanofillers. Meanwhile, the carbon nanotubes and graphene sheets minimize the negative effect of the $\mathrm{BC}$ on the elastic modulus and glass transition temperature of the resin.

\section{EXPERIMENTAL}

\subsection{Materials and preparation of samples:}

The epoxy resin (ER) used in this study was diglycidyl ether of bisphenol A (DGEBA) and 4,4-Methylenedianiline (MDA) was used as curing agent and mixed in a 
stoichiometric ratio. The block copolymer (BC) employed was poly(ethylene glycol)block-poly(propylene glycol)-block-poly(ethylene glycol) (PEO-PPO-PEO), with average molecular weight, $\mathrm{Mw}=8400$ and $80 \mathrm{wt}$. \% ethylene glycol. The $\mathrm{BC}$ possesses a melting point of $57^{\circ} \mathrm{C}$, crystallization temperature of $\sim 36^{\circ} \mathrm{C}$ and a glass transition temperature at $-56{ }^{\circ} \mathrm{C}$. All the chemicals were purchased from Sigma-Aldrich.

MWCNTs and thermally reduced graphene (TRG) were synthetized in our laboratories respectively, by CVD and exfoliation from graphite oxide, according to the procedure described elsewhere[19]. MWCNTs possess an aspect ratio of 3000, a length of $160 \mu \mathrm{m}$, outer diameter of $45 \mathrm{~nm}$ and a specific surface area of $50 \mathrm{~m}^{2} / \mathrm{g}$.

To prepare the cured samples, the block copolymer was added into the epoxy resin at $100{ }^{\circ} \mathrm{C}$ under continuous stirring at three different concentrations: $10 \mathrm{wt} \%$ (10BC), 20 wt. \% (20BC) and 40 wt. \% (40BC) with respect to the epoxy resin. When a homogenous mixture was obtained, $0.25 \mathrm{wt}$ \% (respect to the whole formulation) of carbon nanoparticles (MWCNT or TRG) was added and mechanically stirred at $100{ }^{\circ} \mathrm{C}$ and $2400 \mathrm{rpm}$ for $2 \mathrm{~h}$. In previous publications, we demonstrated that this filler content does not cause large increases on the viscosity of the resin facilitating the casting of the samples.[20] Then, the mixture was degassed at $70{ }^{\circ} \mathrm{C}$ for $1 \mathrm{~h}$ in a vacuum chamber to remove the air bubbles trapped in the system. Finally, the curing agent was added to the mixture at $100{ }^{\circ} \mathrm{C}$ with continuous stirring until the hardener was completely dissolved. MDA was used as a curing agent in a stoichiometric epoxide/amine ratio. The final mixture was then poured into preheated $\left(80^{\circ} \mathrm{C}\right)$ aluminum pans and teflon molds, degassed again at $90{ }^{\circ} \mathrm{C}$, cured at $80^{\circ} \mathrm{C}$ for $8 \mathrm{~h}$, and then post-cured successively at 150 ${ }^{\circ} \mathrm{C}$ for $2 \mathrm{~h}$ and $175^{\circ} \mathrm{C}$ for $1 \mathrm{~h}$. The curing conditions were selected based on previous results reported by Guo et al.[15]. Sample codes indicate first the amount of added BC 
followed by the type pf nanoparticle, for instance: 10BC-TRG indicates that the sample contains 10 wt.\% of BC and TRG.

\subsection{Characterization techniques:}

Calorimetric measurements (DSC) were made on a TA Q200 differential scanning calorimeter in a dry nitrogen atmosphere $(50 \mathrm{ml} / \mathrm{min})$. Indium and tin standards were used for calibration purposes. Samples of 7-10 mg were placed in an aluminum DSC pan. All samples were first heated to $100{ }^{\circ} \mathrm{C}$ from $-60{ }^{\circ} \mathrm{C}$ at $20{ }^{\circ} \mathrm{C} / \mathrm{min}$ and kept at $100{ }^{\circ} \mathrm{C}$ for 2 min to remove the thermal history. Subsequently, they were cooled at a rate of $20{ }^{\circ} \mathrm{C} / \mathrm{min}$ to $-60^{\circ} \mathrm{C}$. Finally, a second heating scan to $250{ }^{\circ} \mathrm{C}$ at the same heating rate was carried out. The crystallization temperature $\left(T_{c}\right)$ was assumed equal to the maximum of the exothermic peak, whereas the melting temperature $\left(T_{m}\right)$ was the minimum of the endothermic peak.

Dynamic mechanical tests (DMA) were performed on a TA Q800 dynamic mechanical analyzer in a single cantilever tension mode. The specimen dimensions were $30 \cdot 5 \cdot 2 \mathrm{~mm}$. The storage modulus $\left(E^{\prime}\right)$ and loss factor $(\tan \delta)$ were measured from room temperature to $250{ }^{\circ} \mathrm{C}$ at a heating rate of $3{ }^{\circ} \mathrm{C} / \mathrm{min}$ and at a frequency of $1 \mathrm{~Hz}$. The glass transition temperature $\left(T_{g}\right)$ was taken at the maximum of the $\tan \delta$ curve. Three measurements were carried out for each sample with a standard error of less than $3 \%$.

Transmission electron microscopy (TEM) images were taken using a TEM Leo 910 microscope at an acceleration voltage of $80 \mathrm{kV}$.The cured samples were cryoultramicrotomed at $-140{ }^{\circ} \mathrm{C}$ with a Leica EM UC6. The ultra-thin films obtained were placed on copper grids and stained with vapor of an aqueous solution of $\mathrm{RuO}_{4}$.

Small angle X-ray scattering (SAXS) experiments were conducted at the Australian Synchrotron on small/wide angle X-ray scattering beam-line utilizing an undulated source that allowed measurement at a very high flux to moderate scattering 
angles and a good flux at the minimum $q$ limit $\left(0.012 \mathrm{~nm}^{-1}\right)$. The intensity profiles were interpreted as the plot of scattering intensity versus scattering vector, $q=(4 / \lambda) \sin (\theta / 2)$ $(\theta=$ scattering angle $)$.

Atomic force microscopy (AFM) was carried out in a Bruker MultiMode 8 SPM instrument in PeakForce QNM mode on a flat trimmed surface generated by ultramicrotomy. AFM images correspond to the adhesion map.

Scanning electron microscopy (SEM) was carried out on a Philips XL30 ESEM at $25 \mathrm{kV}$ to study the morphology and dispersion states of the cryo-fractured samples, which were previously metallized with a $5 \mathrm{~nm}$ coating of gold/palladium.

The fracture toughness of the cured samples was evaluated by means of the plane strain critical stress intensity factor $\left(K_{I C}\right)$. Three point bending tests were carried out with an Instron mechanical tester according to ASTM D5045 standard. Three point bend single notch specimens (SEN-3PB) were prepared by casting and tapping with a fresh blade in order to initiate a pre-crack. For the given configuration where the loading span is 4 times the depth of the sample, $K_{I C}$ can be calculated from equations 1 and 2.

$$
\begin{gathered}
K_{I C}=\frac{P}{B \cdot W^{1 / 2}} \cdot f\left(\frac{a}{W}\right) \\
f\left(\frac{a}{W}\right)=\frac{\left\{6 x^{\frac{1}{2}}\left[1.99-x(1-x)\left(2.15-3.93 x+2.97 x^{2}\right)\right]\right\}}{\left[(1+2 x)(1-x)^{\frac{3}{2}}\right]} \quad x=\left(\frac{a}{W}\right)
\end{gathered}
$$

Where $P$ is the critical load for crack propagation, $B$ the specimen thickness, $W$ the specimen width, $a$ the initial crack length (crack prenotch plus razor tapping notch). 


\section{RESULTS AND DISCUSSION}

\subsection{Miscibility and crystallization:}

The uncured blends and the cured samples in all the range of composition used in this study are transparent at room temperature suggesting that macrophase separation before and during the curing process does not happen (Figure 1). This indicates the miscibility of both components in these compositions.

\section{FIGURE 1}

In figure 2, DSC thermograms of the second heating scan are depicted. The $T_{g}$ of the cured resin gradually decreases with the $\mathrm{BC}$ content in the blend, indicating the miscibility or at least partial miscibility of the two components. This reduction in $T_{g}$ can result from the plasticization effect of the PEO chains that results in a reduction of the crosslinking density of the epoxy resin network. The effect of the nanofillers on the $T_{g}$ will be analyzed by DMTA measurements.

On the other hand, both 20BC and $40 \mathrm{BC}$ unfilled samples present a small endothermic peak in the proximity of the melting point of PEO. Hence, it appears these samples have just enough PEO to start the crystallization of small crystallites of PEO in the resin but not sufficient to cloud the sample. The disappearance of this peak in the loaded samples could be ascribed to three main causes: the first one is the local perturbation of the PEO crystalline order produced by the presence of nanoparticles[21]; the second cause is the lower mobility of polymer chains and higher viscosity of epoxy resin in the presence of MWCNT and TRG[20]. Thirdly, it has been reported that carbon nanoparticles accelerate the curing reaction of epoxy resins[22], therefore PEO chains have less time to crystalize in systems with quick curing reactions. 


\section{FIGURE 2}

\subsection{Dynamic mechanical properties:}

Figure 3 shows the dynamic mechanical response of all the samples. As already mentioned, the addition of $\mathrm{BC}$ significantly decreases the $T_{g}$ due to the lower crosslinking degree of the PEO rich areas and the highly mobile microphases of PPO. However, in all cases the $T_{g}$ of the nanoparticle filled mixtures is higher compared to the unfilled system (see values in table 1). Graphene sheets produced by the thermal reduction of graphite oxide present different type of oxidative species attached on their

surface like: epoxy, hydroxyl and carbonyl groups [23] making TRG the most effective filler achieving increments higher than $20{ }^{\circ} \mathrm{C}$ with only a $0.25 \mathrm{wt} . \%$ of TRG in the formulation. These changes in the $T_{g}$ are attributed to a strong filler-matrix interface, thus nanofillers with functional groups on their surface, like the TRG, produce a larger increment on the $T_{g}$.

It is also important to point out how the storage modulus of the materials with nanoparticles is higher in the glassy and rubbery region balancing the negative effect of the $\mathrm{BC}$ on this property.

In the case of the $40 \mathrm{BC}$ samples, the levels of $\mathrm{BC}$ result in an important plasticizing effect, as can be observed in the Tg values of the table 1 for the unloaded systems. In this system, the stiffening effect of graphene is significantly more evident due to the higher possible van der Waals interactions between the functional groups on the surface of the filler and the higher number of PEO chains as well as the more stable filler dispersion in the presence of high contents of BCs.

\section{FIGURE 3 AND TABLE 1}


Gonzalez-Dominguez et al. [24] observed a similar thermal behavior of an epoxy resin containing SWNTs wrapped with a commercial pluronic block copolymer based on PEO-PPO-PEO. They observed a reduction of the $T_{g}$ of $20{ }^{\circ} \mathrm{C}$ on a sample with a similar BC content as the present study. The subsequent inclusion of oxidized SWNTs considerably improved this negative effect on the $T_{g}$.

\subsection{Morphology:}

The morphology of the cured epoxy resin containing different amounts of BC was examined by TEM. Figure 4 shows the TEM micrographs for the 10BC, 20BC and 40BC. The sample with the smallest amount of BC displays the most homogeneous morphology, while the blends with $\mathrm{BC}$ content above 10 wt. \% show a more heterogeneous morphology at the nanoscale. The tiny black spots are the PPO nanodomains, rendered black by the preferential staining with $\mathrm{RuO}_{4}$ compared to the cured ER matrix[25]. The 40BC sample (figure 4c) shows a hierarchical nanostructure formed by the PPO spherical domains with diameters of about 20-30 nm dispersed within the continuous ER matrix. The dark grey areas are the epoxy resin rich in PEO and the grey areas the epoxy resin rich phase. This hierarchical nanostructure was previously described by Guo et al.[15].

\section{FIGURE 4}

The hierarchical nanostructure can be considered as a nanophase separated system driven by a reaction-induced microphase separation (RIMS) during the curing process due to the immiscibility of the PPO and the weaker miscibility of PEO in the cross-linked thermosetting resin[26]. At the beginning of the curing reaction the $\mathrm{BC}$ is miscible with the resin, as the reaction continues, the PPO central blocks start to 
nucleate in self-assembled nanodomains. Eventually, in the fully cured resin, PEO is located in the proximity of the PPO domains forming an interphase of partially cured epoxy resin rich in PEO acting as a bridge between the PPO nano-separated phase and the fully cured epoxy resin matrix[27]. As the miscibility of PEO in the fully cured resin is not as good as in the pre-cured resin, high amounts of the $\mathrm{BC}$ could lead to the orientation of some PEO chains in the right direction to partially crystallize.

SAXS experiments were also performed to further characterize the morphology of the $\mathrm{BC}$ loaded resin. Their profiles are depicted in figure 5. For the plain epoxy resin and the 10BC samples no scattering peaks are observed. A broad scattering peak can be seen for the $20 \mathrm{BC}$ and $40 \mathrm{BC}$ samples indicating the presence of phase separated structures at the nanometer scale. These peaks are centered at the scattering vector $q$ for a long spacing of $23 \mathrm{~nm}$, corresponding to the average distance between neighboring spherical domains.

\section{FIGURE 5}

The effect of the addition of carbon nanoparticles on the morphology of the system was analyzed by AFM on an ultramicrotomed surface. Figure 6 shows the morphology obtained by tapping mode AFM for the samples without nanoparticles. As already observed in the TEM analysis, the 10BC sample presents a very homogeneous morphology at both micro and nanoscale. While, 20BC only shows the nanoseparated PPO domains at the nanoscale, seen in the $1 \mathrm{x} 1 \mu \mathrm{m}$ image. Finally, the $40 \mathrm{BC}$ sample presents a separated phase, with size domains around 0.6 to $1 \mu \mathrm{m}$, which corresponds to the PEO-rich microphases, seen in the $5 \times 5 \mu \mathrm{m}$ image, and the PPO nanodomains $1 \times 1$ $\mu \mathrm{m}$ image (PEO-rich microphases were intentionally avoided at the $1 \mathrm{x} 1 \mu \mathrm{m}$ scale image). 


\section{FIGURE 6}

Figure 7 shows the effect of the nanoparticles on the morphology of the nanostructured epoxy resin containing $40 \mathrm{wt} . \%$ of BC. The addition of carbon nanoparticles inhibits the microphase separation of PEO-rich microphases as evidenced by the $5 \times 5 \mu \mathrm{m}$ scale images, resulting in a more homogeneous morphology[24]. On the other hand, the morphology of the samples at a nanoscale (1x1 $\mu \mathrm{m}$ frames) is not affected by the local perturbation of the nanoparticles and the spherical nanodomains of PPO are found in the samples examined. In all cases the size of the spheres is around $20-30 \mathrm{~nm}$ as also observed in the figure $6(1 \times 1 \mu \mathrm{m}$ image $)$ of the $40 \mathrm{BC}$ sample.

\section{FIGURE 7}

On the other hand, PEO-PPO-PEO BCs have also been employed to disentangle CNTs through non-covalent interactions between the blocks and the CNTs. This noncovalent functionalization is aimed to increase the stability of individual CNTs in organic solvents followed by evaporation and curing of the epoxy resin. [28] A second approach to increase the dispersibility of CNTs using PEO-PPO-PEO is through wrapping processes. [24] However, the quantities of BC employed in these studies is not enough to generate a fully nanostructured system. In this work we employ larger quantities of $\mathrm{BC}$ which lead to the nanostructuration of the matrix and to the increase of the dispersibility of the nanoparticles.

\subsection{Toughness:}

The dispersion state of the nanoparticle was analyzed by SEM on cryofractured surfaces. The micrographs in figure 8 clearly show the different fracture mechanisms of 
the samples. For the neat epoxy resin, with neither BC nor nanofiller (figure 8a), we can observe the classical brittle fracture with a flat surface and steps between cleavages on parallel planes. The addition of $40 \mathrm{wt}$. $\%$ of BC (figure $8 \mathrm{~b}$ ) makes the fracture surface much rougher but it is still possible to observe some parallel planes. Finally, the fracture for the 40 BC-TRG and 40BC-MWCNT samples (figure 8c and d) show a ductile behavior without the previous evidences of brittle fractures. In both samples, TRG and MWCNTs are well dispersed and spread out through the epoxy matrix without forming agglomerates. In particular, the TRG can be found in stacks of a few graphene layers with a wrinkled geometry.

\section{FIGURE 8}

Mechanical properties of the cured mixtures were evaluated measuring the critical stress intensity factor $\left(K_{I C}\right)$. Figure 9 shows the positive effect of the $\mathrm{BC}$ and nanoparticles in the $K_{I C}$. The largest enhancement is obtained with the 40BC-TRG sample with an increment of $K_{I C}$ higher than $55 \%$ compared to the neat epoxy resin (see values of $K_{I C}$ in table 1). TRG outperforms MWCNT due to the better adhesion of the graphene to the matrix produced by their surface functionalization, their high specific surface area and their wrinkle and planar geometry resulting in a better mechanical interlocking with the polymer chains and a more impeded crack propagation[17, 20]. Unexpectedly, the enhancement among the samples with 20 wt. $\%$ and 40 wt. $\%$ of BC is almost insignificant compared to the improvement achieved with the $20 \mathrm{wt}$. \%. This fact could be the result of a saturation effect of the system that requires further analysis.

FIGURE 9 
When it comes to enhancing the toughness of epoxy resins using rigid particles, like TRG or MWCNTs, or a soft second phase, like a BC, there are several toughening mechanisms to take into account. Shear yielding is one of the most accepted mechanisms in polymers modified by a second phase. It involves the plastic deformation and cavitation of the particles and/or the matrix at the crack tip under the application of stresses[29]. Another toughening mechanism is the crack path deflection, in this case, the proposed role of the particles is to cause the crack to deviate from its plane. Such deviation results in an increased surface area reducing the mode I character of the opening of the crack[30]. The particle bridging mechanism supposes that the particles act as bridges compressing the crack path[31]. The microcracking mechanism supposes that the particles or the second phase generate microcracks increasing the toughness and originating tensile yielding and larger deformations[32]. Finally, in the crack pinning mechanism the rigid or soft particles behave as impenetrable objects that cause the crack to bow out, consuming extra energy to the crack propagation[33]. In the case of using nanoparticles as a toughening agent, particle pull-out should also be considered between the possible toughening mechanisms[34].

However, none of the mechanisms explained above occur in an isolated way, more likely a combination of all of them may take place at the same time. For this reason, the integration of both toughening routes, the formation of a softer second phase and the addition of nanoparticles, would involve a larger number of toughening mechanisms.

\section{CONCLUSIONS}

Novel self-assembled nanocomposites based on blends of an epoxy resin and an amphiphilic triblock copolymer filled with carbon nanotubes and graphene were 
successfully prepared. A hierarchical nanostructure, with spherical PPO domains of 20$30 \mathrm{~nm}$ diameter homogeneously dispersed in the epoxy resin, was formed during cure reaction. A PEO-rich microphase was originated at a microscale for the blends above 20 wt. \% of BC located at the interphase of PPO domains. The presence of the carbon nanoparticles appeared to inhibit this microphase separation, while no effect was observed in either the size of the PPO nanodomains or their geometry. However, the carbon nanoparticles had a strong effect on the mechanical properties of the material. A synergic effect between the $\mathrm{BC}$ and the nanoparticles was observed, which gave rise to a significant increase of the toughness of the resin. In addition, the $T_{g}$ of the resin was increased in more than $20^{\circ} \mathrm{C}$ upon the addition of TRG. TRG is the most effective property enhancer due to the better adhesion of the functionalized graphene layers with the matrix and their wrinkled and planar geometry.

\section{ACKNOWLEDGMENTS}

The work was supported by the Spanish Ministry of Science and Innovation (MICINN) under project MAT 2010-18749. MMG thanks the JAE-Pre grant from the

CSIC. The SAXS measurements were conducted on the SAXS beam-line at the Australian Synchrotron, Victoria, Australia, and we would like to thank Dr Nigel Kirby for his technical assistance.

\section{REFERENCES}


[1] Rallini M, Natali M, Torre L, Kenny J. Effect of boron carbide nanoparticles on the fire reaction and fire resistance of carbon fiber/epoxy composites. Polymer. 2013;54(19):5154-65.

[2] Chiacchiarelli L, Rallini M, Monti M, Puglia D, Kenny J, Torre L. The role of irreversible and reversible phenomena in the piezoresistive behavior of graphene epoxy nanocomposites applied to structural health monitoring. Compos Sci Technol. 2013;80:73-9.

[3] Katnam KB, Stevenson JPJ, Stanley WF, Buggy M, Young TM. Tensile strength of two-part epoxy paste adhesives: Influence of mixing technique and micro-void formation. Int J Adhes Adhes. 2011;31(7):666-73.

[4] Zhang K, Gu Y, li M, Zhang Z. Effect of rapid curing process on the properties of carbon fiber/epoxy composite fabricated using vacuum assisted resin infusion molding. Materials \& Design. 2014;54:624-31.

[5] Thomas R, Yumei D, Yuelong H, Le Y, Moldenaers P, Weimin Y, et al. Miscibility, morphology, thermal, and mechanical properties of a DGEBA based epoxy resin toughened with a liquid rubber. Polymer. 2008;49(1):278-94.

[6] Chaudhary S, Surekha P, Kumar D, Rajagopal C, Roy PK. Amine-functionalized poly(styrene) microspheres as thermoplastic toughener for epoxy resin. Polym Compos. 2014:DOI: 10.1002/pc.22927.

[7] Sangermano M, Messori M, Martin Gallego M, Rizza G, Voit B, Galleco MM. Scratch resistant tough nanocomposite epoxy coatings based on hyperbranched polyesters. Polymer. 2009;50(24):5647-52.

[8] Gojny FH, Wichmann MHG, Köpke U, Fiedler B, Schulte K. Carbon nanotubereinforced epoxy-composites: enhanced stiffness and fracture toughness at low nanotube content. Compos Sci Technol. 2004;64(15):2363-71. 
[9] Jordan J, Jacob K, Tannenbaum R, Sharaf M, Jasiuk I. Experimental trends in polymer nanocomposites — a review. Mater Sci Eng, A. 2005;393(1-2):1-11.

[10] Lipic P, Bates F, Hillmyer M. Nanostructured thermosets from self-assembled amphiphilic block copolymer/epoxy resin mixtures. J Am Chem Soc. 1998;120(35):8963-70.

[11] Ocando C, Tercjak A, Dolores Martin M, Martín MD, Ramos J, Campo Mn, et al. Morphology development in thermosetting mixtures through the variation on chemical functionalization degree of poly(styrene-b-butadiene) diblock copolymer modifiers. Thermomechanical properties. Macromolecules. 2009;42(16):6215-24.

[12] Hameed N, Guo Q, Xu Z, Hanley T, Mai Y-W. Reactive block copolymer modified thermosets: highly ordered nanostructures and improved properties. Soft Matter. 2010;6(24):6119-29.

[13] Ruiz Perez L, Royston G, Ryan A. Toughening by nanostructure. Polymer. 2008;49(21):4475-88.

[14] Mijovic J, Shen M, Sy J, Mondragon I. Dynamics and morphology in nanostructured thermoset network/block copolymer blends during network formation. Macromolecules. 2000;33(14):5235-44.

[15] Guo Q, Thomann R, Gronski W, Thurn-Albrecht T. Phase behavior, crystallization, and hierarchical nanostructures in self-organized thermoset blends of epoxy resin and amphiphilic poly(ethylene oxide)-block-poly(propylene oxide)-block-poly(ethylene oxide) triblock copolymers. Macromolecules. 2002;35(8):3133-44.

[16] Builes DH, Hernández-Ortiz JP, Corcuera MA, Mondragon I, Tercjak A. Effect of poly(ethylene oxide) homopolymer and two different poly(ethylene oxide-bpoly(propylene oxide)-b-poly(ethylene oxide) triblock copolymers on morphological, 
optical, and mechanical properties of nanostructured unsaturated polyester. ACS Appl Mater interfaces. 2013;6(2):1073-81.

[17] Rafiee MA, Rafiee J, Wang Z, Song H, Yu Z-Z, Koratkar N. Enhanced Mechanical Properties of Nanocomposites at Low Graphene Content. ACS Nano. 2009;3(12):388490.

[18] Mahrholz T, Stängle J, Sinapius M. Quantitation of the reinforcement effect of silica nanoparticles in epoxy resins used in liquid composite moulding processes. Composites Part A: Applied Science and Manufacturing. 2009;40(3):235-43.

[19] Bon SB, Valentini L, Verdejo R, Garcia Fierro JL, Peponi L, Lopez-Manchado MA, et al. Plasma Fluorination of Chemically Derived Graphene Sheets and Subsequent Modification With Butylamine. Chem Mater. 2009;21(14):3433-8.

[20] Martin-Gallego M, Bernal MM, Hernandez M, Verdejo R, Lopez-Manchado MA. Comparison of filler percolation and mechanical properties in graphene and carbon nanotubes filled epoxy nanocomposites. Eur Polym J. 2013;49(6):1347-53.

[21] Chatterjee T, Yurekli K, Hadjiev VG, Krishnamoorti R. Single-walled carbon nanotube dispersions in poly(ethylene oxide). Adv Funct Mater. 2005;15(11):1832-8. [22] Puglia D, Valentini L, Kenny JM. Analysis of the cure reaction of carbon nanotubes/epoxy resin composites through thermal analysis and Raman spectroscopy. J Appl Polym Sci. 2003;88(2):452-8.

[23] Schniepp HC, Li J-L, McAllister MJ, Sai H, Herrera-Alonso M, Adamson DH, et al. Functionalized Single Graphene Sheets Derived from Splitting Graphite Oxide. The Journal of Physical Chemistry B. 2006;110(17):8535-9.

[24] González-Domínguez JM, Ansón-Casaos A, Díez-Pascual AM, Ashrafi B, Naffakh M, Backman D, et al. Solvent-free preparation of high-toughness epoxy-SWNT composite materials. ACS Appl Mater interfaces. 2011;3(5):1441-50. 
[25] Trent JS, Scheinbeim JI, Couchman PR. Ruthenium tetraoxide staining of polymers for electron microscopy. Macromolecules. 1983;16(4):589-98.

[26] Li X, Fu W, Wang Y, Chen T, Liu X, Lin H, et al. Solid-state NMR characterization of unsaturated polyester thermoset blends containing PEO-PPO-PEO block copolymers. Polymer. 2008;49(12):2886-97.

[27] Sun P, Dang Q, Li B, Chen T, Wang Y, Lin H, et al. Mobility, miscibility, and microdomain structure in nanostructured thermoset blends of epoxy resin and amphiphilic poly(ethylene oxide)-block-poly(propylene oxide)-block-poly(ethylene oxide) triblock copolymers characterized by solid-state NMR. Macromolecules. 2005;38(13):5654-67.

[28] Grady BP. Recent developments concerning the dispersion of carbon nanotubes in polymers. Macromol Rapid Commun. 2010;31(3):247-57.

[29] Kinloch AJ, Shaw SJ, Tod DA, Hunston DL. Deformation and fracture behaviour of a rubber-toughened epoxy: 1. Microstructure and fracture studies. Polymer. $1983 ; 24(10): 1341-54$.

[30] Faber KT, Evans AG. Crack deflection processes-I. Theory. Acta Metall. 1983;31(4):565-76.

[31] Sigl LS, Mataga PA, Dalgleish BJ, McMeeking RM, Evans AG. On the toughness of brittle materials reinforced with a ductile phase. Acta Metall. 1988;36(4):945-53. [32] Williams S, Beaumont PWR, Evans AG. On the toughness of particulate filled polymers. J Mater Sci. 1985;20(10):3668-74.

[33] Pearson R, Yee A. Toughening mechanisms in thermoplastic-modified epoxies: 1. Modification using poly(phenylene oxide). Polymer. 1993;34(17):3658-70. [34] Fiedler B, Gojny FH, Wichmann MHG, Nolte MCM, Schulte K. Fundamental aspects of nano-reinforced composites. Compos Sci Technol. 2006;66(16):3115-25. 
a

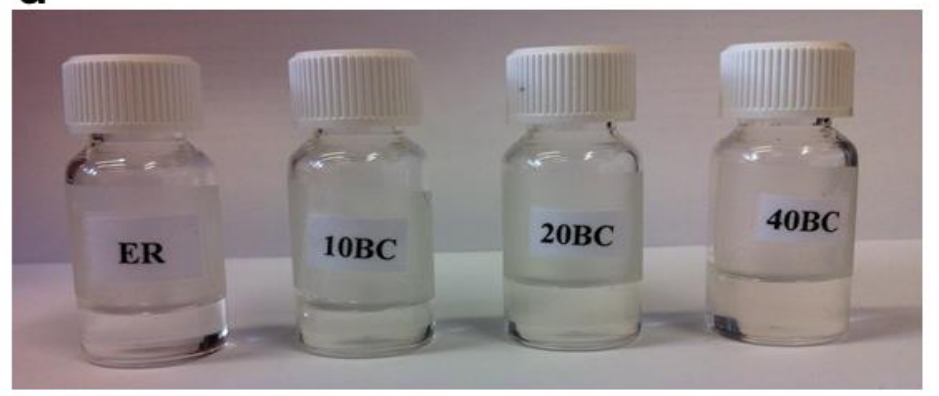

b

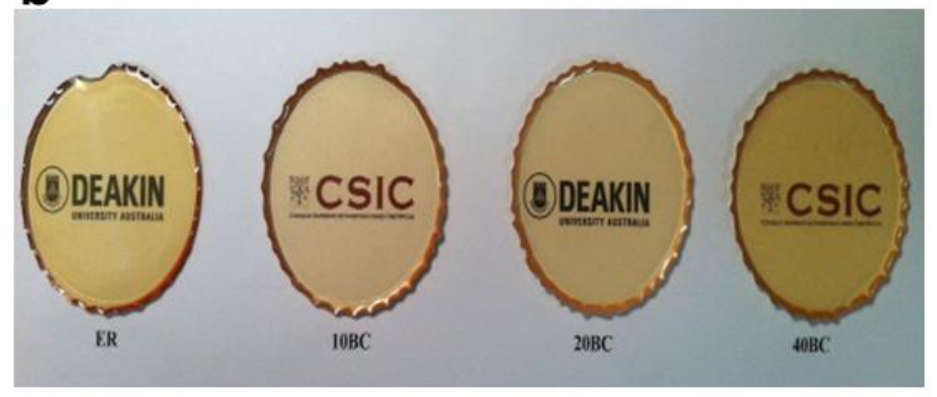

Figure 1. Digital image at room temperature of the samples in the a) uncured and b) cured states (2 mm thick). 


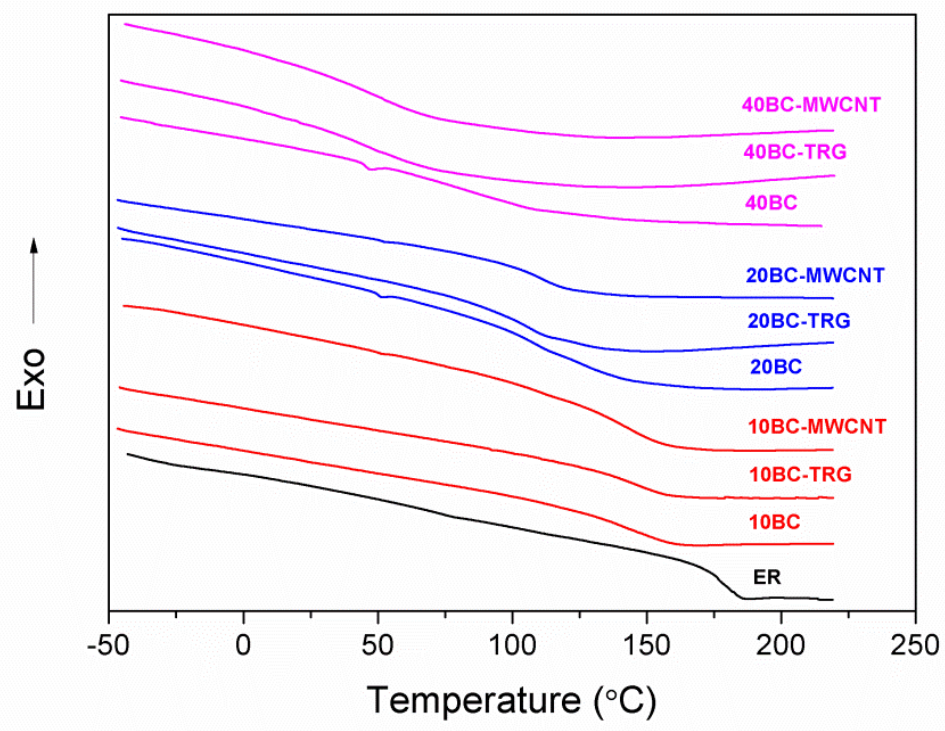

Figure 2. DSC thermograms. 

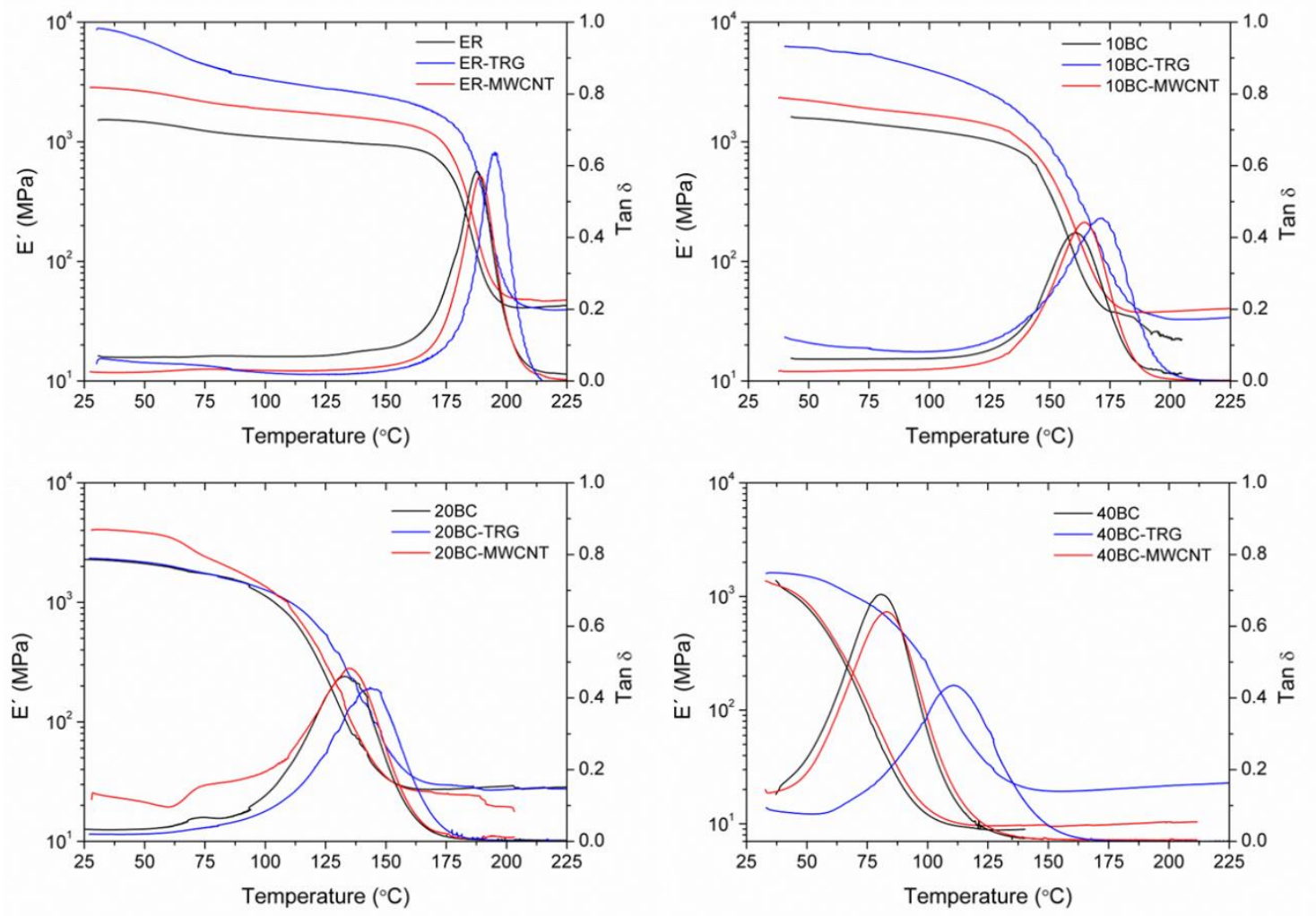

Figure 3. Dynamic mechanical curves. 

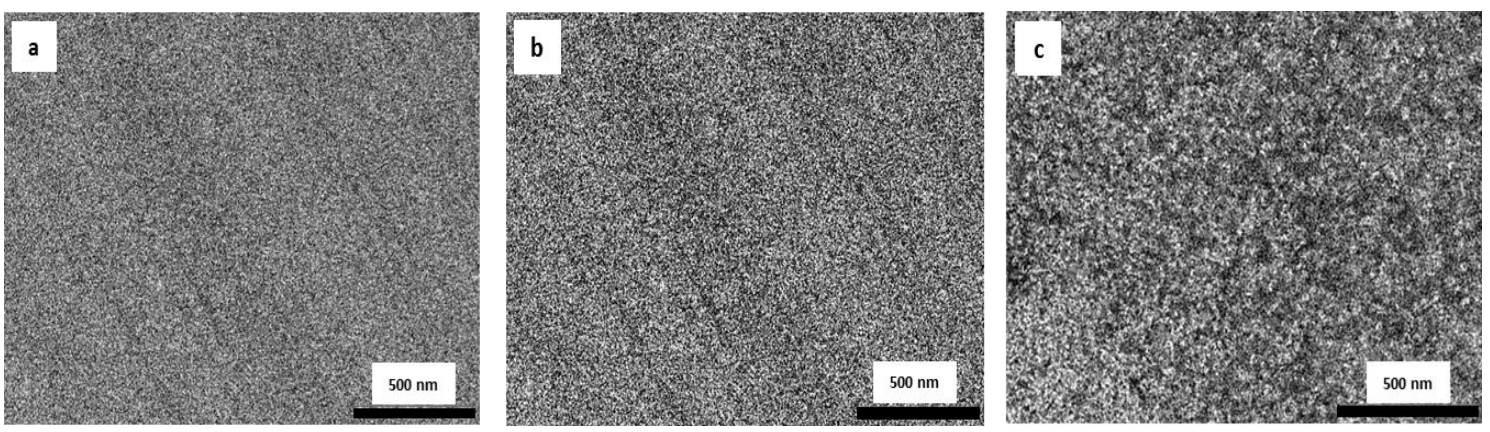

Figure 4. TEM images of a) $10 \mathrm{BC}$, b) $20 \mathrm{BC}$ and d) $40 \mathrm{BC}$. 


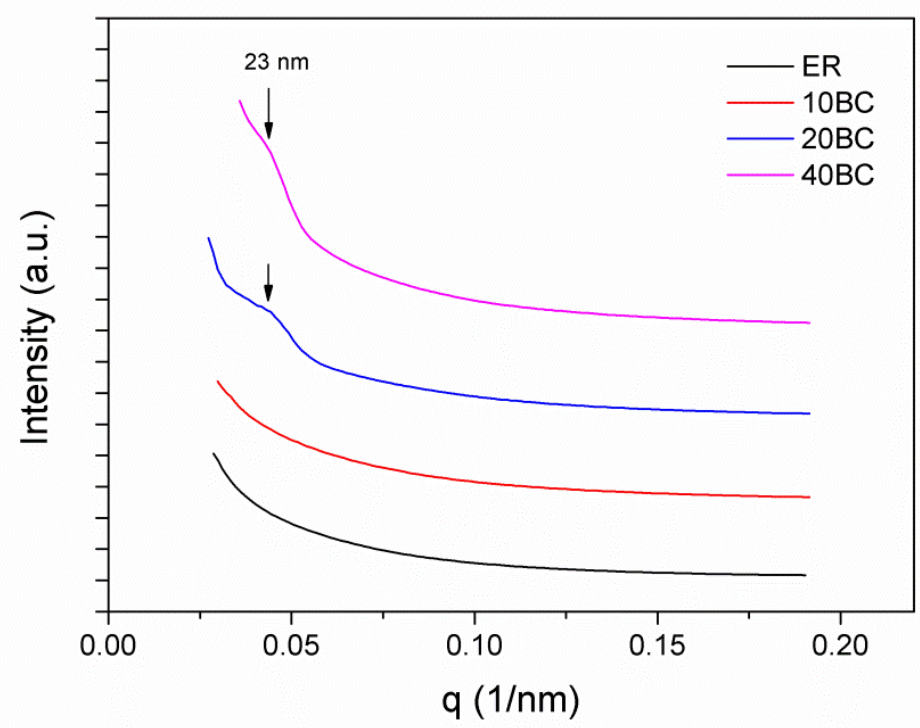

Figure 5. SAXS profiles of the neat epoxy resin, 10BC, 20BC and 40BC. 


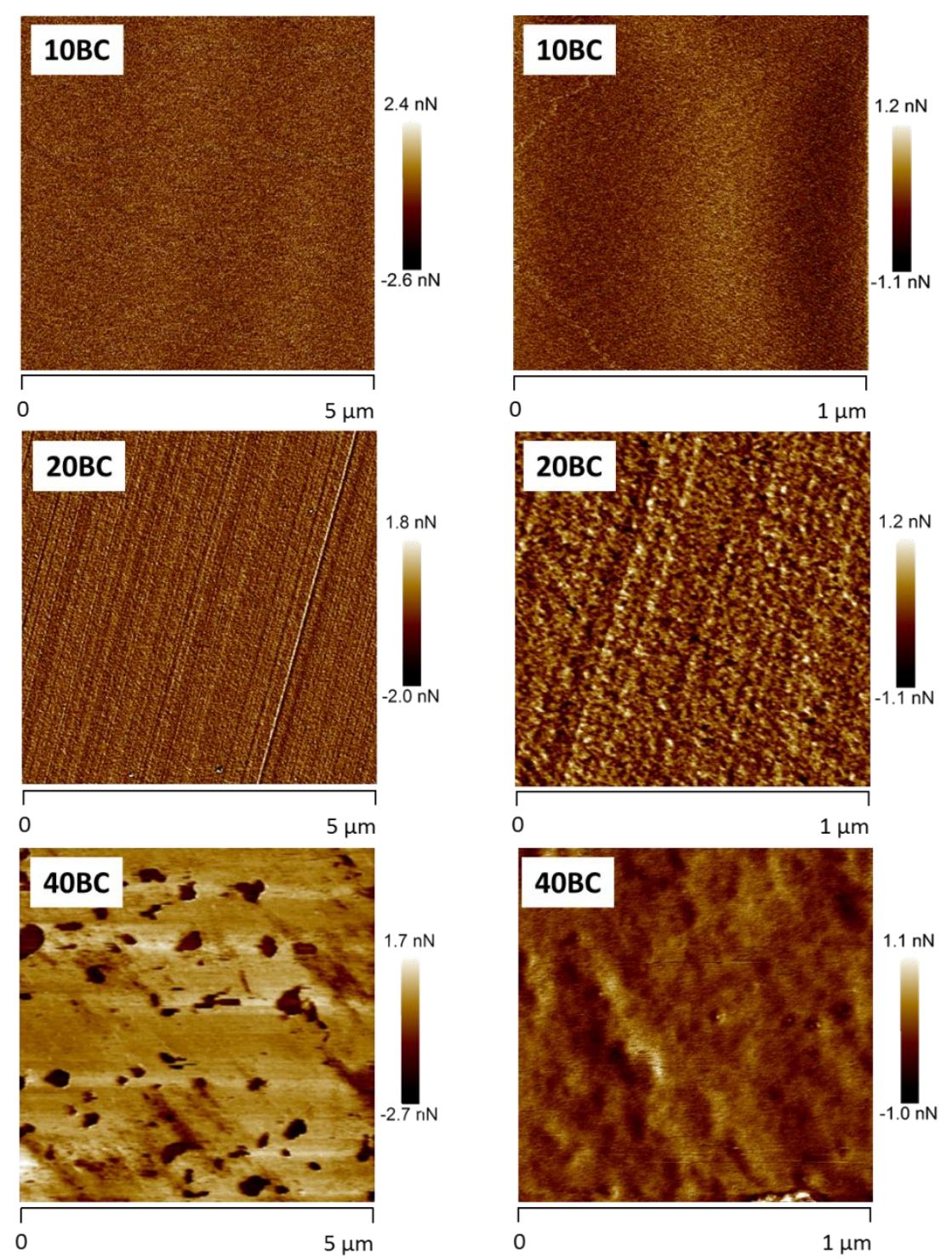

Figure 6. Tapping mode AFM images at $5 \times 5 \mu \mathrm{m}$ and $1 \times 1 \mu \mathrm{m}$ scales. 

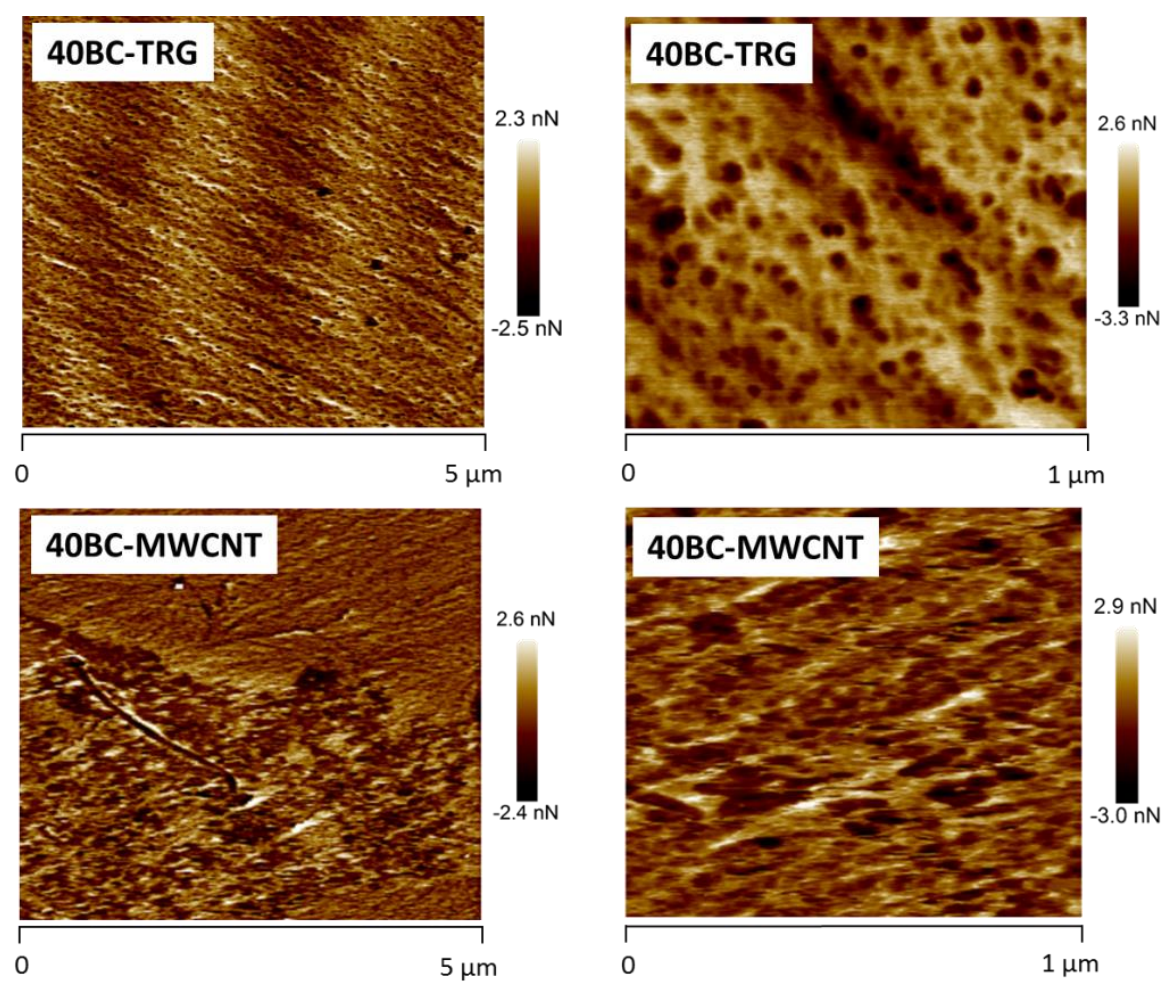

Figure 7. Tapping mode AFM images of 40BC-TRG and 40BC-MWCNT at $5 \times 5 \mu \mathrm{m}$ and $1 \mathrm{x} 1 \mu \mathrm{m}$ scales. 

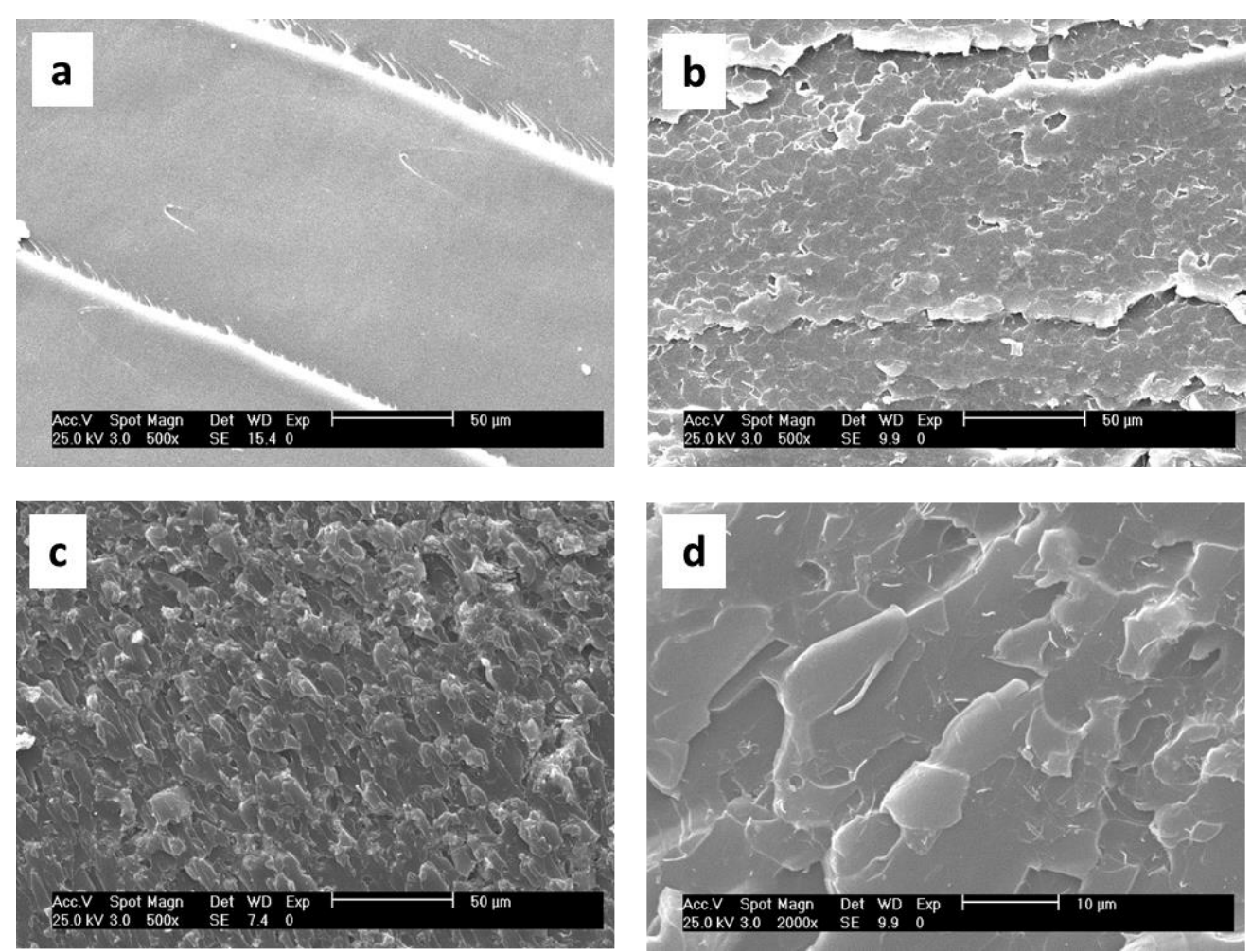

Figure 8. SEM images of a) neat epoxy resin, b) 40BC, c) 40BC-TRG and d) 40BCMWCNT. 


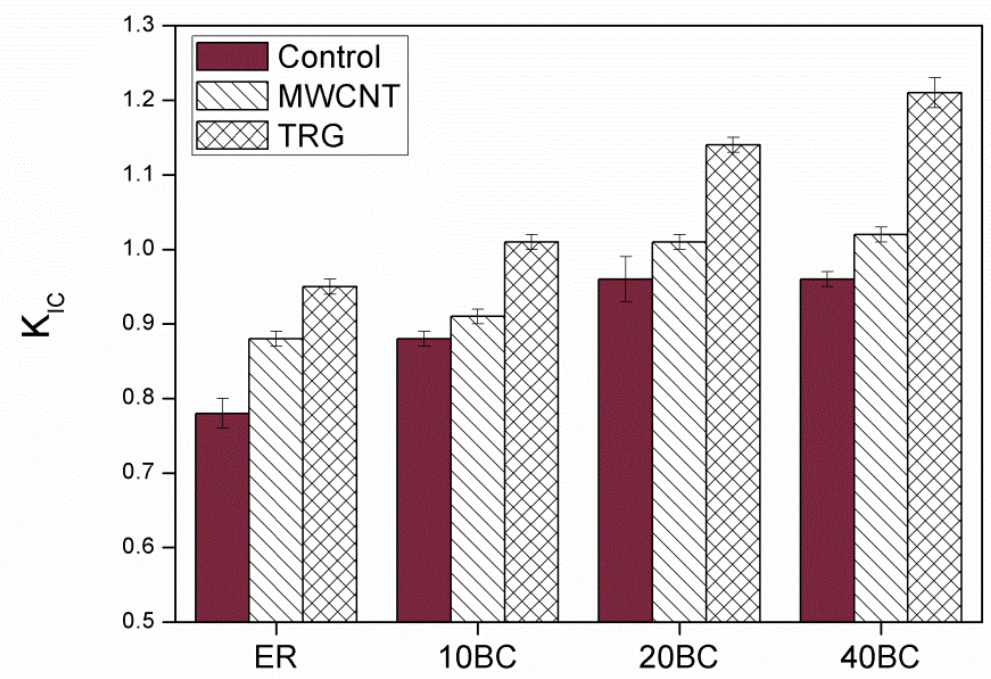

Figure 9. $K_{I C}$ comparison. 


\begin{tabular}{ccccc}
\hline & & Control & TRG & MWCNT \\
\hline \multirow{2}{*}{ ER } & $T_{g}\left({ }^{\circ} \mathrm{C}\right)$ & 187 & 195 & 189 \\
& $K_{I C}\left(\mathrm{MPa} \mathrm{m}^{1 / 2}\right)$ & $0.78 \pm 0.02$ & $0.95 \pm 0.01$ & $0.88 \pm 0.01$ \\
\multirow{2}{*}{ 10BC } & $T_{g}\left({ }^{\circ} \mathrm{C}\right)$ & 160 & 171 & 164 \\
& $K_{I C}\left(\mathrm{MPa} \mathrm{m}^{1 / 2}\right)$ & $0.88 \pm 0.01$ & $1.01 \pm 0.01$ & $0.91 \pm 0.01$ \\
\multirow{2}{*}{ 20BC } & $T_{g}\left({ }^{\circ} \mathrm{C}\right)$ & 133 & 143 & 135 \\
& $K_{I C}\left(\mathrm{MPa} \mathrm{m}^{1 / 2}\right)$ & $0.96 \pm 0.03$ & $1.14 \pm 0.01$ & $1.01 \pm 0.01$ \\
& $T_{g}\left({ }^{\circ} \mathrm{C}\right)$ & 81 & 109 & 84 \\
40BC & $K_{I C}\left(\mathrm{MPa} \mathrm{m}^{1 / 2}\right)$ & $0.96 \pm 0.01$ & $1.21 \pm 0.02$ & 1.010 .01 \\
& & & &
\end{tabular}

Table 1. $T_{g}$ and $K_{I C}$ values. 